NASA/TM-2000-210626

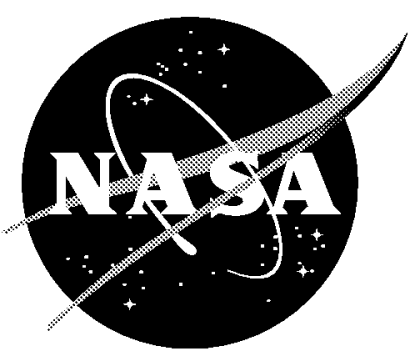

RF Loading Effects of Aircraft Seats in an Electromagnetic Reverberating Environment

\author{
Truong X. Nguyen
}

Langley Research Center, Hampton, Virginia 
The NASA STI Program Office ... in Profile

Since its founding, NASA has been dedicated to the advancement of aeronautics and space science. The NASA Scientific and Technical Information (STI) Program Office plays a key part in helping NASA maintain this important role.

The NASA STI Program Office is operated by Langley Research Center, the lead center for NASA's scientific and technical information. The NASA STI Program Office provides access to the NASA STI Database, the largest collection of aeronautical and space science STI in the world. The Program Office is also NASA's institutional mechanism for disseminating the results of its research and development activities. These results are published by NASA in the NASA STI Report Series, which includes the following report types:

- TECHNICAL PUBLICATION. Reports of completed research or a major significant phase of research that present the results of NASA programs and include extensive data or theoretical analysis. Includes compilations of significant scientific and technical data and information deemed to be of continuing reference value. NASA counterpart of peer-reviewed formal professional papers, but having less stringent limitations on manuscript length and extent of graphic presentations.

- TECHNICAL MEMORANDUM. Scientific and technical findings that are preliminary or of specialized interest, e.g., quick release reports, working papers, and bibliographies that contain minimal annotation. Does not contain extensive analysis.

- CONTRACTOR REPORT. Scientific and technical findings by NASA-sponsored contractors and grantees.
- CONFERENCE PUBLICATION. Collected papers from scientific and technical conferences, symposia, seminars, or other meetings sponsored or co-sponsored by NASA.

- SPECIAL PUBLICATION. Scientific, technical, or historical information from NASA programs, projects, and missions, often concerned with subjects having substantial public interest.

- TECHNICAL TRANSLATION. Englishlanguage translations of foreign scientific and technical material pertinent to NASA's mission.

Specialized services that complement the STI Program Office's diverse offerings include creating custom thesauri, building customized databases, organizing and publishing research results ... even providing videos.

For more information about the NASA STI Program Office, see the following:

- Access the NASA STI Program Home Page at http://www.sti.nasa.gov

- E-mail your question via the Internet to help@sti.nasa.gov

- Fax your question to the NASA STI Help Desk at (301) 621-0134

- Phone the NASA STI Help Desk at (301) 621-0390

- Write to: NASA STI Help Desk NASA Center for AeroSpace Information 7121 Standard Drive Hanover, MD 21076-1320 
NASA/TM-2000-210626

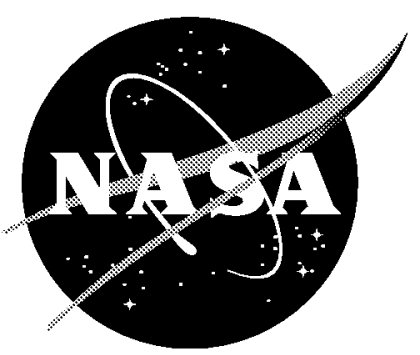

\title{
RF Loading Effects of Aircraft Seats in an Electromagnetic Reverberating Environment
}

\author{
Truong X. Nguyen
}

Langley Research Center, Hampton, Virginia

National Aeronautics and

Space Administration

Langley Research Center

Hampton, Virginia 23681-2199 
Available from:

NASA Center for AeroSpace Information (CASI)

7121 Standard Drive

Hanover, MD 21076-1320

(301) 621-0390
National Technical Information Service (NTIS) 5285 Port Royal Road

Springfield, VA 22161-2171

(703) 605-6000 


\title{
RF LOADING EFFECTS OF AIRCRAFT SEATS IN AN ELECTROMAGNETIC REVERBERATING ENVIRONMENT
}

\author{
Truong Nguyen, NASA Langley Research Center, Hampton, VA
}

\begin{abstract}
Loading effects of aircraft seats in an electromagnetic reverberating environment are investigated. The effects are determined by comparing the reverberation chamber's insertion losses with and without the seats. The average per-seat absorption cross-sections are derived for coach and first class seats, and the results are compared for several seat configurations. An example is given for how the seat absorption cross-sections can be used to estimate the loading effects on the RF environment in an aircraft passenger cabin.
\end{abstract}

\section{Introduction}

There has been significant interest in the effects on aircraft digital avionics due to radio frequency (RF) electromagnetic fields. These fields may come from sources external to the airplane such as high power radars, or possibly from carry-on personal electronic devices (PEDs) inside the plane. Electromagnetic fields can induce currents on circuits causing undesirable effects, which may include system shutdown in digital equipment. In order to characterize the electromagnetic coupling from RF sources on the internal electromagnetic environment, it is desirable to understand the effects of different loading sources in the aircraft cavity. These sources may be due to RF absorption or leakage from aircraft seats, human bodies, electrical wires, windows, and others. This paper addresses the effects caused by aircraft seats, which are of interest since there are large numbers of them on commercial aircraft.

Recent NASA Langley Research Center's acquisition and conversion of a 20 year old Boeing 757 airplane to a research vehicle briefly made available a number of aircraft seats. Since actual testing inside the aircraft was impractical for this purpose, evaluation in a reverberation chamber (also called mode-stirred chamber) becomes the next best option. A high $Q$ cavity like a reverberation chamber is expected to be much different from a low $Q$ environment like in an aircraft. However, as it will be shown later, a parameter called seat absorption cross-section, that is independent of the cavity's Q, can be extracted and used in predicting the effects of the seats in an actual aircraft environment.

\section{Approach}

\section{Description}

The twenty year old seats used in this experiment included ten first class and eight coach class seats. The first class seats come in pairs, where as the coach class seats come in two rows of three and one row of two chairs.

To address the effects of aircraft seats, testing on an actual airframe would be ideal but expensive. Rather, it is advantageous to utilize a mode-stirred chamber instead, since electromagnetic fields in a mode-stirred chamber behave very similar statistically to those within an aircraft body [1].

The mode-stirred method has been suggested as a thorough and cost effective method for testing avionics products for HIRF compliance. It is also very effective for measuring $\mathrm{RF}$ absorption and total radiated power. Readers unfamiliar with the modestirred chamber testing techniques are recommended to review reference $[2,3]$. 
Using a reverberation chamber, the chamber's average gain is first measured without the seats to establish a baseline representing all of the losses in the chamber not associated with the aircraft seats. The average gain is then measured again but with the seats in the chamber. The differences between the two measurements are the effects associated only with the presence of the seats. The results are then used to derive the seats' absorption cross-section $\left\langle\sigma_{a}\right\rangle$, which will be shown to be independent of the $\mathrm{Q}$ of reverberation environment. $\left\langle\sigma_{a}\right\rangle$ can later be used to estimate the loading effects due to the seats on the Q of another reverberating environment.

\section{Theory}

The inverse of the quality factor $Q$ of a reverberation chamber is the sum of the inverse of the $Q$ of all loss factors in the chamber [4] including the seats. Or,

$$
\frac{1}{Q_{N_{\text {_seats }}}^{\text {Total }}}=\frac{1}{Q_{0}^{\text {Total }}}+\frac{1}{Q_{N_{-} \text {seats }}}
$$

where $Q_{N_{-} \text {seats }}$ is associated with loss due to the seats only. $Q_{0}^{\text {Total }}$ is the total chamber's quality factor without the seats, and $Q_{N_{-} \text {seats }}^{\text {Total }}$ is the total chamber's quality factor with the additional presence of the aircraft seats. Both $Q_{N_{-} \text {seats }}^{\text {Total }}$ and $Q_{0}^{\text {Total }}$ can be readily calculated from measuring the chamber gain with and without the seats. From [4],

$$
Q_{N_{-} \text {seats }}=\frac{2 \pi V}{N \lambda}\left\langle\sigma_{a}\right\rangle,
$$

where $\mathrm{N}$ is the number of seats; $\left\langle\sigma_{a}\right\rangle$ is the absorption cross section per seat assuming the losses for all the seats of the same kind are the same; $V$ is chamber's volume; and $\lambda$ is the wavelength.

$\left\langle\sigma_{a}\right\rangle$, we get:

$$
\left\langle\sigma_{a}\right\rangle=\frac{2 \pi V}{N \lambda}\left[\frac{1}{Q_{N_{-} \text {seats }}^{\text {total }}}-\frac{1}{Q_{0}^{\text {total }}}\right] .
$$

The chamber quality factor $Q$ can be expressed as

$$
\begin{aligned}
Q & =\left(\frac{16 \pi^{2} V}{n_{1} n_{2} \lambda^{3}}\right)\left(\frac{\left\langle P_{\text {rec }}\right\rangle}{P_{\text {input }}}\right) \\
& =\left(\frac{16 \pi^{2} V}{n_{1} n_{2} \lambda^{3}}\right)\langle G\rangle,
\end{aligned}
$$

where $\eta_{1}, \eta_{2}$ transmit and receive antennas efficiency,

$\left\langle P_{\text {rec }}\right\rangle \quad$ the average power at the receive antenna (Watts),

$P_{\text {input }}$ power input to the chamber at transmit antenna's terminal (Watts), and

$\langle G\rangle \quad$ average chamber gain, or $=\frac{\left\langle P_{\text {rec }}\right\rangle}{\left.P_{\text {input }}\right\rangle}$.

The procedure for measuring the average chamber gain is described in [2]. In short, the average chamber gain is the ratio of the average power coupled out of the chamber via an efficient receive antenna to the power delivered into the chamber. The antenna efficiency $\eta_{1}, \eta_{2}$ are typically about 0.75 for $\log$ periodic antennas and 0.95 for dual ridge horn antenna [5]. Ideally, they should be unity for $100 \%$ efficiency. For simplicity, they are assumed to be unity for this purpose since they are difficult to measure. In addition, we also assume that the antennas are well matched, and no mismatch corrections are necessary. The power transmitted into and coupled out of the chamber can simply be measured at the antenna terminals.

Substitute $\{4\}$ into $\{3\}$,

$$
\left\langle\sigma_{a}\right\rangle=\frac{\eta_{1} \eta_{2} \lambda^{2}}{8 \pi N}\left[\frac{1}{\left\langle G_{N_{-} \text {seats }}\right\rangle}-\frac{1}{\left\langle G_{0}\right\rangle}\right] \text {, }
$$


where $\left\langle G_{0}\right\rangle$ and $\left\langle G_{N_{-} \text {seats }}\right\rangle$ are the average chamber gains with and without the seats, respectively.

\section{Test Methods}

To use equation $\{5\}$, one needs to know the average chamber gain with and without the seats, $\left\langle G_{N_{-} \text {seats }}\right\rangle$ and $\left\langle G_{0}\right\rangle$ respectively. Chamber gain is measured by taking the ratio of the received power against the transmitted power. Typically, only a small amount of power at the desired frequency is injected into a reverberation chamber through the transmit antenna. The receive antenna measures the power at the receive antenna over a complete stirrer revolution. The receive power is then normalized to (or divided by) the input power to yield chamber gain for that frequency. If the maximum value of receive power is used in the computation, the ratio is called the maximum chamber gain. If the average receive power is used, the result is called the average chamber gain $\langle G\rangle$.

The chamber gain measurement was performed using two different methods: "modetune" for frequencies below $1 \mathrm{GHz}$ and "modestir" for frequencies above $1 \mathrm{GHz}$.

In theory, there is little difference between the two methods, except with how the input power is measured and maintained constant as the paddle rotates. In the modestirred method, the forward power is maintained constant as the stirrer rotates. In mode-tuned method, the net input power (forward power minus reflected power) is maintained constant as the stirrer rotates.

In practice, the mode-tuned method is much more difficult to implement since both the forward power and reflected power are measured, and the power is adjusted to maintain constant net power for every paddle positions. This is necessary at lower frequencies (near the chamber start frequency, or about $100 \mathrm{MHz}$ ) as the forward and reflected powers fluctuate significantly with the paddle rotations.

In contrast, at higher frequencies (typically above $1 \mathrm{GHz}$ ), both the forward and reflected power levels remain relatively constant with paddle rotations. In addition, the reflected power is low given efficient and matched transmit antenna. The mode-stirred method is typically used in this range of frequency since only the forward power is monitored, and therefore easier to perform.

\section{Test Set Up}

The seats were tested in six configurations: $3,6,8$ coach class seats, and 2, 6, 10 first class seats. They were arranged approximately half a meter off the floor in the middle of the $14.3 m \times 7.0 m \times 2.9 m(47 \times 23 \times$ 9.5 feet) mode-stirred test chamber as shown in figure 1. For better repeatability, they were positioned at least a third to a half of a wavelength away from any conducting surface as according to the guidelines in [2]. However, this set up was not entirely realistic as many of the seats were close to the airframe body in an actual aircraft.

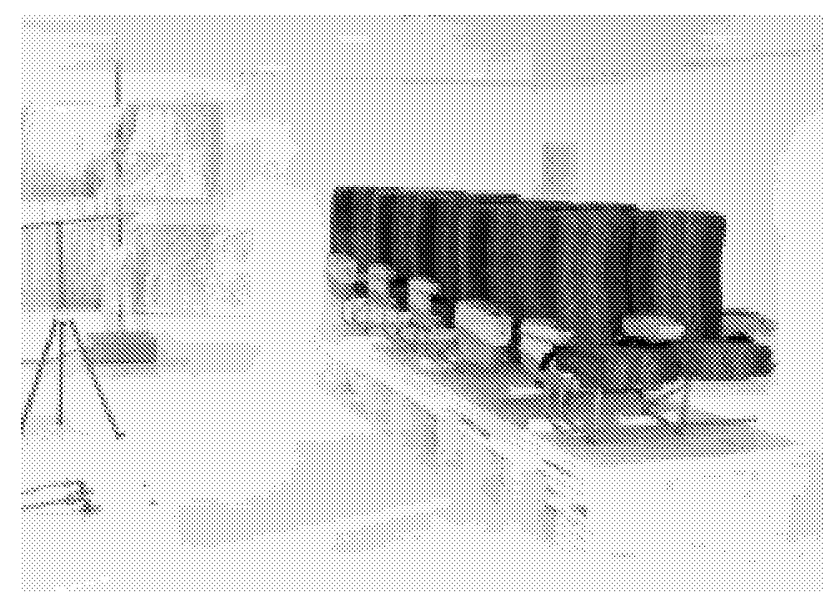

\section{Figure 1: Ten first class seats in a reverberation chamber}

A pair of log period antennas were used for frequencies below $1 \mathrm{GHz}$. Above $1 \mathrm{GHz}$ up to $8 \mathrm{GHz}$, a pair of dual-ridge-horns antennas were used. The antennas were positioned in such a way as to prevent direct coupling 
between antennas, and so as not to point directly at the seats.

\section{Analysis and Results}

Both the maximum chamber gain data (from peak spectrum analyzer's reading) and the average chamber gain data (from the average spectrum analyzer's readings) were collected. However, only the average chamber gain data are presented in this paper since the analysis on maximum chamber gain requires further theoretical developments.

In figures 2-3, the average chamber gain curves, along with their best fit curves, are shown compared with empty chamber data to demonstrate the effects of the seats in a reverberation chamber. Average empty chamber gain data is shown with no offset. Others are shown with 10, 20 and $30 \mathrm{~dB}$ offsets for better clarity and to prevent curves from riding on top of one another. For coach class seats, figure 2 shows average chamber gains for no seat (with no offset), with 3 seats $(-10 \mathrm{~dB}$ offset), with 6 seats ( $-20 \mathrm{~dB}$ offset), and with 8 seats $(-30 \mathrm{db}$ offset). For first class seats, figure 3 shows chamber gains for no seat (with no offset), with 2 seats (-10dB offset), with 6 seats $(-20 \mathrm{~dB}$ offset), and with 10 seats $(-30 \mathrm{db}$ offset). In addition, the best-fit curve for empty chamber data is plotted with the same offsets ($10,-20$ and $-30 \mathrm{~dB}$ ) to illustrate the effects of increasing the number of seats.

In figures 2 and 3 , the trends show chamber loss compared to an empty chamber increases as the number of seats increases. Even though the effects of the seats on the average chamber gain are small in $\mathrm{dB}$ value, they may have a significant impact on the $Q$ of the aircraft due to the large number of seats installed in a typical aircraft. Figures 2 and 3 also show that the losses are very broadband, so they can be easily represented with just few points across the frequency span.

If one were to divide the total seat loss by the number of seats, the results would be a value that may be mistakenly identified as the loss per seat. This value tends to decrease as the number of seats in the chamber increases, therefore is not useful in practice. This phenomenon also indicates that the effects on the chamber gain decrease with the chamber gain, or chamber quality factor $\mathrm{Q}$.

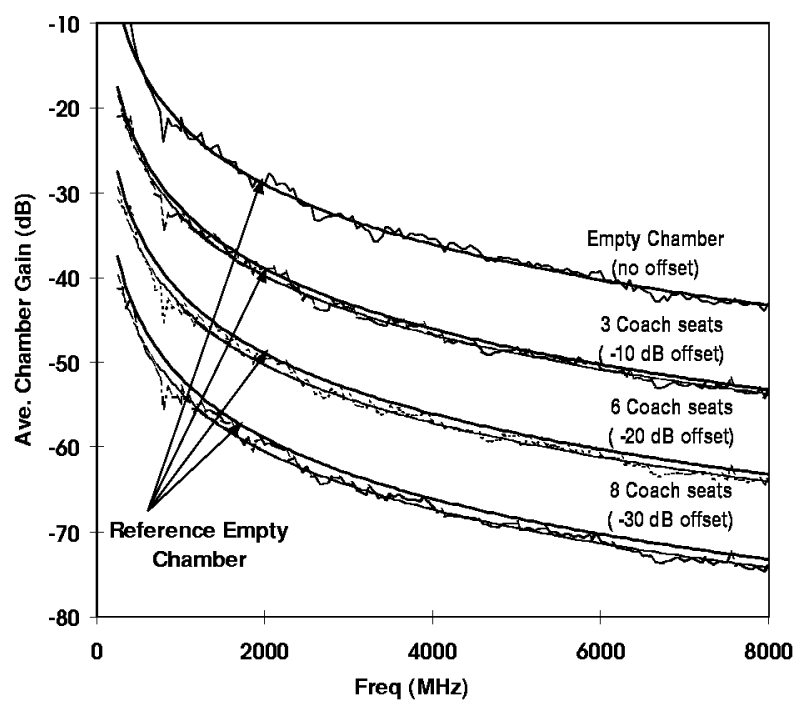

Figure 2. Average Chamber Gain with 3,6,8 Coach Class Seats and best-fit curves

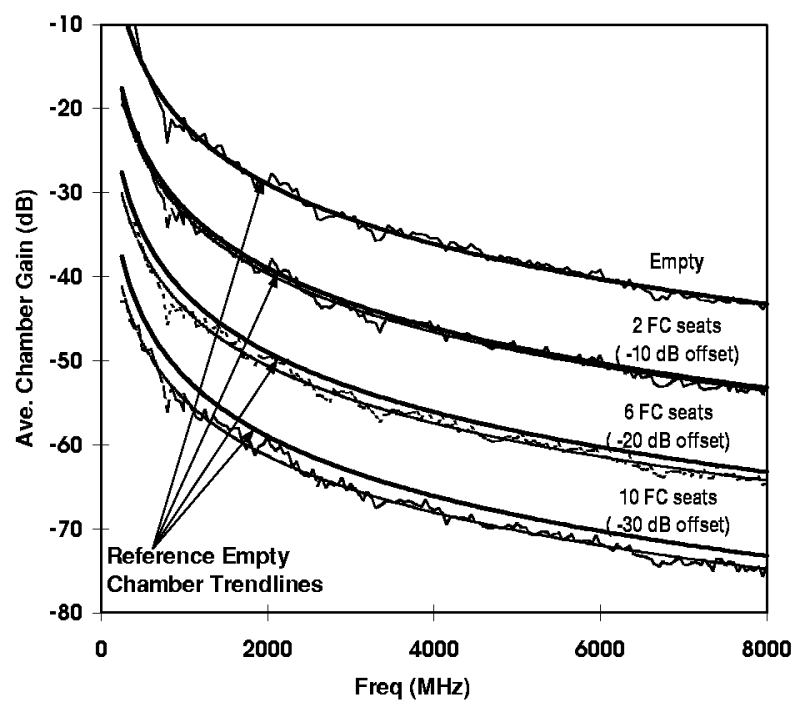

Figure 3. Average Chamber Gain with 2,6,10 First Class Seats and best-fit curves

Instead, equation 5 describes the absorbing cross section parameter that is valid with any chamber $\mathrm{Q}$. This value depends only on the $Q_{N_{-} \text {seats }}$, which is independent of 
chamber $\mathrm{Q}$ as shown in equation 1. However, its effect on the $Q$ depends on the $Q$ value of the environment. The lower the cavity $Q$, the less the effect the seats will have on it.

As an illustration, if the $Q$ of the environment is low, the seat loss may not contribute much to the overall cavity gain since other types of chamber losses (like losses due to wall, windows, etc.) dominates the cavity gain value. Since $Q$ is directly related to the cavity gain, the presence of the seats does not affect the $Q$ significantly. If the $Q$ is high, however, the RF loss caused by the seat is now a major contributor to the overall loss. Therefore, adding or removing seats significantly affects the cavity $\mathrm{Q}$.

Equation 5 can be applied directly to the average chamber gain data in figures 2 and 3 to provide absorbing cross section value. However, the result would be extremely noisy since both the empty chamber data and chamber with seats data are inherently noisy. The difference between two noisy sets of data would be even noisier. Since the magnitude difference between the two sets of data is already small, the noise in the calculation results would be larger than the result itself.

Since average seat loss is expected to be slowly varying with frequency, various techniques can be used to reduce noise in the results. Our approach is to best fit each gain curve with an analytical function, then apply equation 5 to the smoothed functions to obtain the average absorbing cross section.

The results are shown in figure 4 and 5 for comparing $\left\langle\sigma_{a}\right\rangle$ for various seat configurations. The averages of the results are also shown as references. Both figures show that the results agree well, with the first class seat results showing better agreement.

This approach also appears to be valid for cavity losses due to other sources, including human body RF absorption, wiring, etc. These losses can be measured in a reverberation chamber, and the results can be used to predict the effects in an actual aircraft environment. One just has to ensure the frequency is such that both the laboratory and aircraft environments are overmoded [2] and are statistically similar, typically implying there are at least several hundred cavity modes in each of the cavities. The use of this approach for undermoded cavities has not been demonstrated.

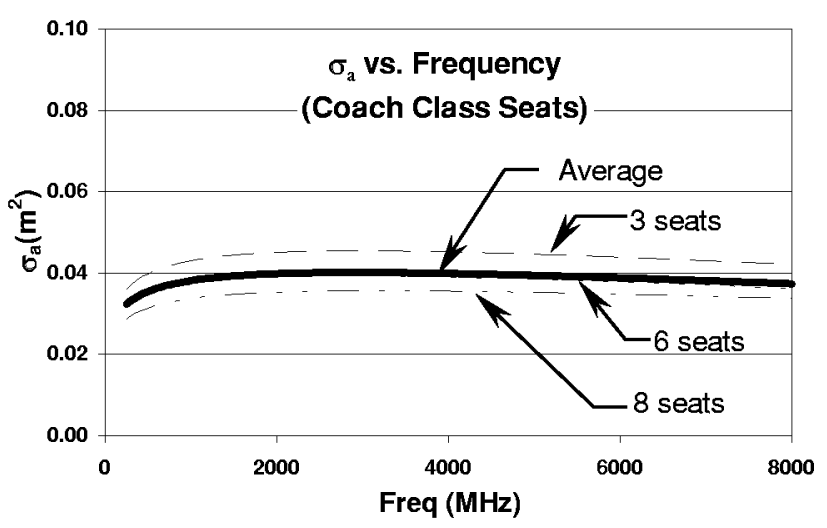

Figure 4. Coach Class Seat's Absorbing Cross-Section $\left\langle\sigma_{a}\right\rangle$

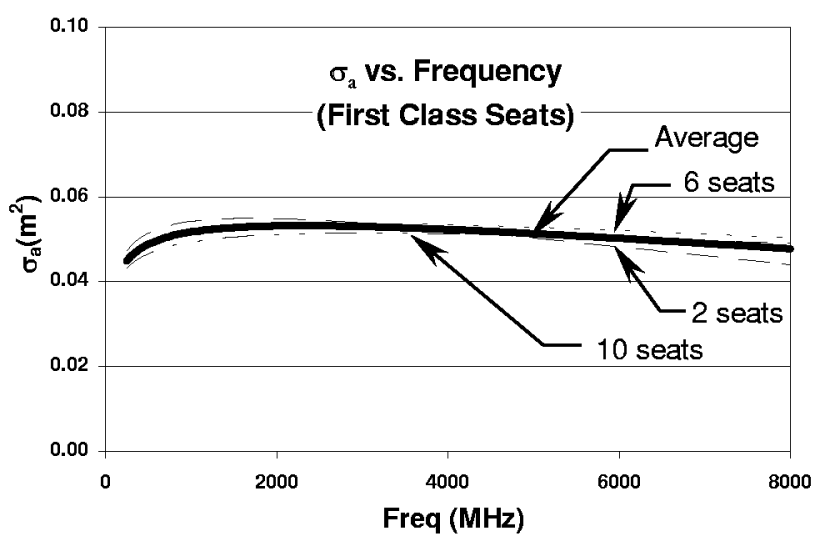

Figure 5. First Class Seat's Absorbing Cross-Section $\left\langle\sigma_{a}\right\rangle$

\section{Application to Aircraft Environment}

This section illustrates how $\left\langle\sigma_{a}\right\rangle$ is used to estimate the RF loading effects of aircraft seats in the aircraft passenger cabin. It is necessary to know the $Q$ of the cabin, either empty or with the seats. Since there is currently no such published data available for a Boeing 
757 , we use Q data for an empty Boeing 707720B [6] with no seats. An assumption made is that the Q's for both airplanes are about the same. Further, it is assumed that the cavity gain can be scaled with the volume ratio between the two airplanes. The assumptions appeared reasonable since both airplanes were built by the same manufacturer, and the volumes were on the same order. In fact, rough estimates of the internal volumes are about $573 \mathrm{~m}^{3}$ for a B757 and $464 \mathrm{~m}^{3}$ for B707. Also, we assume there are 200 coach class seats in a Boeing 757 for this calculation.

In [6], several techniques were used for measuring the cavity $\mathrm{Q}$ of a passenger cabin, and the results do not agree with each other very well. The reasons have not been resolved. For this illustration, however, we use the highest envelope of $\mathrm{Q}$ data for the highest cavity gain. This tends to exaggerate the effects of the seats slightly. The assumed values for $\mathrm{Q}$ are shown in table $1 .\left\langle\sigma_{a}\right\rangle$ takes an approximate value of 0.04 at all frequencies for simplicity, which is reasonable according to figure 4. Applying equation 5 and solving for $\left\langle G_{N \text { sasas }}\right\rangle /\left\langle G_{0}\right\rangle$ in $\mathrm{dB}$, one will arrive at the table 1 below:

Table 1: Estimated reduction in average cavity gain in a B757 with 200 seats

\begin{tabular}{|r|c|c|c|}
\hline $\begin{array}{c}\text { Freq } \\
(\mathrm{MHz})\end{array}$ & $\mathbf{Q}$ & $\left\langle\sigma_{a}\right\rangle$ & $\begin{array}{c}\left\langle G_{N_{\text {-seats }}}\right\rangle /\left\langle G_{0}\right\rangle \\
(\mathrm{dB})\end{array}$ \\
\hline 100 & 50 & 0.04 & $\mathbf{- 1 . 2 6}$ \\
\hline 225 & 110 & 0.04 & $\mathbf{- 1 . 2 3}$ \\
\hline 300 & 137 & 0.04 & $\mathbf{- 1 . 1 6}$ \\
\hline 600 & 237 & 0.04 & $\mathbf{- 1 . 0 2}$ \\
\hline 925 & 350 & 0.04 & $\mathbf{- 0 . 9 8}$ \\
\hline 1000 & 375 & 0.04 & $-\mathbf{0 . 9 7}$ \\
\hline 1800 & 850 & 0.04 & $\mathbf{- 1 . 1 9}$ \\
\hline 3200 & 1250 & 0.04 & $\mathbf{- 1 . 0 1}$ \\
\hline 5000 & 1800 & 0.04 & $-\mathbf{0 . 9 4}$ \\
\hline 5800 & 1975 & 0.04 & $-\mathbf{0 . 8 9}$ \\
\hline
\end{tabular}

From table 1, the presence of the 200 seats reduced the average cavity gain by about
$1.25 \mathrm{~dB}$ at $100 \mathrm{MHz}$ to about $0.9 \mathrm{~dB}$ at 5.8 $\mathrm{GHz}$. The loss is not significant to have a major impact on the RF environment, and is barely observable.

The assumption is the environment behaves similarly to a mode-stirred chamber statistically, and that there is no direct transmit and receive antenna coupling. In the case of RF coupling from a personal electronic device onto a wire, depending on the distance between them, direct coupling effects may dominate the mode-stirred effects, then this approximation does not apply.

\section{Conclusion}

Absorption cross-sections of a set of aircraft seats in a mode-stirred environment were derived from measured cavity gains. They are independent of the quality factor Q of the chamber in which the parameters were measured and are relatively constant with frequency. They can be used to predict the effects of the seats on the electromagnetic reverberating environments in an aircraft. The same approach can be used in characterizing absorbing bodies in aircraft and other reverberating environments.

\section{Acknowledgement}

The author would like to thank Mr. Reuben Williams and Mr. Kenneth Dudley, both of NASA Langley, and Ms. Sandra Koppen, Lockheed Martin, for their supports in acquiring the seats and in software development. Special thanks to Mr. Michael Hatfield, NSWC, for providing technical directions leading to the understanding of chamber Q.

\section{References}

[1] Hatfield, M.O.; Freyer, G.J.; Johnson, D.M.; Farthing, C.L.; "Demonstration test of the electromagnetic reverberation characteristics of a transport size 
aircraft," NSWC Dahlgren Division, Report No. NSWCDD/TR-93/339, 1993.

[2]. Crawford, M.L. and Koepke, G.H., "Design, Evaluation and Use of a Reverberation Chamber for Performing Electromagnetic Susceptibility/ Vulnerability Measurements," NBS Tech. Note 1092, 1986.

[3] "Environmental Conditions and Test Procedures for Airborne Equipment," RTCA/DO-160D, July 29, 1997.

[4] Hill, D.A; Ma M.T..; Ondrejka A.R.;Riddle B.F.; Crawford M.L.; Johnk R.T., "Aperture Excitation of Electrically Large, Lossy Cavities," IEEE Trans. On Electromagnetic Compatibility, Vol 36, No. 3, August 1994.

[5] Ladbury, J.; Koepke, G.; and Camell, D., "Evaluation of the NASA Langley Research Center Mode-Stirred Chamber Facility," NIST Technical Note 1508, 1999

[6] Hatfield, M.O.; Johnson, D.M.; Capt. Loughry, T.A.; Ondrejka, A.R; Johnk, R.T; Freyer, G.J; Slocum, M.B. "Phase II Demonstration test of the electromagnetic reverberation characteristics of a transport size aircraft," NSWC Dahlgren Division, Report No. NSWCDD/TR97/84, 1997. 
Public reporting burden for this collection of information is estimated to average 1 hour per response, including the time for reviewing instructions, searching existing date sources, gathering and maintaining the data needed, and completing and reviewing the collection of information. Send comments regarding this burden estimate or any other aspect of this collection of information, including suggestions for reducing this burden, to Washington Headquarters Services, Directorate for Information Operations and

Reports, 1215 Jefferson Davis Highway, Suite 1204, Arlington, VA 22202-4302, and to the Office of Management and Budget, Paperwork Reduction Project (0704-0188), Washington, DC 20503.

\begin{tabular}{|l|l|l|}
\hline 1. AGENCY USE ONLY (Leave blank) & $\begin{array}{l}\text { 2. REPORT DATE } \\
\text { December } 2000\end{array}$ & $\begin{array}{l}\text { 3. REPORT TYPE AND DATES COVERED } \\
\text { Technical Memorandum }\end{array}$ \\
\hline
\end{tabular}

\begin{tabular}{l|l|l} 
4. TITLE AND SUBTITLE & 5. FUNDING NUMBERS
\end{tabular}

RF Loading Effects of Aircraft Seats in an Electromagnetic Reverberating Environment

WU 522-14-21-02

\author{
6. AUTHOR(S) \\ Truong X. Nguyen
}

7. PERFORMING ORGANIZATION NAME(S) AND ADDRESS(ES)

8. PERFORMING ORGANIZATION

REPORT NUMBER

NASA Langley Research Center

Hampton, VA 23681-2199

L-18047

9. SPONSORING/MONITORING AGENCY NAME(S) AND ADDRESS(ES)

10. SPONSORING/MONITORING AGENCY REPORT NUMBER

National Aeronautics and Space Administration

Washington, DC 20546-0001

NASA/TM-2000-210626

\title{
11. SUPPLEMENTARY NOTES
}

12a. DISTRIBUTION/AVAILABILITY STATEMENT

12b. DISTRIBUTION CODE

Unclassified-Unlimited

Subject Category $33 \quad$ Distribution: Nonstandard

Availability: NASA CASI (301) 621-0390

13. ABSTRACT (Maximum 200 words)

Loading effects of aircraft seats in an electromagnetic reverberating environment are investigated. The effects are determined by comparing the reverberation chamber's insertion losses with and without the seats. The average per-seat absorption cross-sections are derived for coach and first class seats, and the results are compared for several seat configurations. An example is given for how the seat absorption cross-sections can be used to estimate the loading effects on the RF environment in an aircraft passenger cabin.

\section{SUBJECT TERMS}

Reverberation; Mode-stirred; Aircraft seat; Absorption-cross-section; Immunity; Susceptibility; HIRF; EMC; Quality factor; RF absorption

\begin{tabular}{l} 
15. NUMBER OF PAGES \\
12 \\
\hline 16. PRICE CODE \\
A03 \\
\hline $\begin{array}{l}\text { 20. LIMITATION } \\
\text { OF ABSTRACT } \\
\text { UL }\end{array}$ \\
\hline
\end{tabular}

